\title{
Epidemiologia molecular de bacilos Gram-negativos multidroga resistente produtores de carbapenemases isoladas de diferentes sítios de infecção
}

\author{
Molecular epidemiology of carbapenemase-producing multidlrug-resistant gram-negative bacilli \\ isolated from different infection sites
}

Epidemiología molecular de bacilos gram-negativos multirresistentes productores de carbapenemasas aislados de diferentes sitios de infección

\author{
Cynthia Regina Pedrosa Soares \\ ORCID: https://orcid.org/0000-0001-8915-859X \\ Universidade Federal de Pernambuco, Brasil \\ E-mail: cynthiaregina@msn.com \\ Felipe Rogério Ferreira da Silva \\ ORCID: https://orcid.org/0000-0002-2898-0501 \\ Hospital da Restauração Governador Paulo Guerra, Brasil \\ E-mail: felipe_rogerio_fs@hotmail.com \\ Jorge Belém Oliveira Júnior \\ ORCID: https://orcid.org/0000-0002-8130-1598 \\ Universidade Federal de Pernambuco, Brasil \\ E-mail: junniorbiologia@hotmail.com \\ Paulo Sérgio Ramos de Araújo \\ ORCID: https://orcid.org/0000-0002-7839-0737 \\ Universidade Federal de Pernambuco, Brasil \\ E-mail:psergiora@gmail.com \\ Elza Ferreira Firmo \\ ORCID: https://orcid.org/0000-0001-5042-4483 \\ Universidade Federal de Pernambuco, Brasil \\ E-mail: elzafirmo@gmail.com
}

\begin{abstract}
Resumo
A resistência a carbapenemases em bacilos gram-negativas (BGN) tornou-se um problema mundial, elevando a taxa de morbidade e mortalidade. O método automatizado foi utilizado para identificação e suscetibilidade dos isolados. E o método molecular foi aplicado na detecção de bacilos gram-negativas (BGN) produtoras de carbapenemase. Um total de 205 BGN foram recuperados a partir de diferentes amostras clínicas, resistentes a carbapenemases. Os genes de resistência bla $_{\mathrm{KPC}}(57,5 \%)$, bla $a_{\mathrm{VIM}}(30,2 \%)$, bla $a_{\mathrm{GES}}(17 \%)$, bla $_{\mathrm{NDM}}(15 \%)$ e bla SPM $_{\mathrm{SP}}(2,4 \%)$ foram recuperados a partir de isolados clínicos. O gene bla $a_{\mathrm{IMP}}$ não foi detectado em nenhum dos isolados. É preocupante que Pseudomonas aeruginosa e Acinetobacter baumannii representem a maioria dos isolados $(61,6 \%)$ recuperados de infecções de diferentes sítios, com alta resistência a carbapenêmicos, carregando simultaneamente os genes bla $a_{\mathrm{KPC}}, b l a_{\mathrm{GES}}$ e $b l a_{\mathrm{VIM}}$, assim como encontrados também em Enterobactericeae. A carbapenemase mais prevalente foi bla $a_{\mathrm{KPC}}$ e $b l a_{\mathrm{VIM}}$, seguida de $b l a_{\mathrm{NDM}}$ dentre os isolados multidroga resistentes. Esses resultados são um ameaça à saúde pública, configurando altas taxas de resistência, limitando as opções terapêuticas.
\end{abstract}

Palavras-chave: Bactérias gram-negativas; Carbapenemase; Multidroga resistente; Epidemiologia molecular.

\begin{abstract}
Resistance to carbapenemases in gram-negative bacilli (BGN) has become a worldwide problem, increasing the rate of morbidity and mortality. The automated method was used for identification and susceptibility of isolates. And the molecular method was applied in the detection of gram-negative bacilli (BGN) producing carbapenemase. A total of 205 BGN were recovered from different carbapenemase-resistant clinical specimens. Resistance genes $b l a \mathrm{KPC}$ $(57,5 \%)$, bla $_{\mathrm{VIM}}(30,2 \%)$, bla $_{\mathrm{GES}}(17 \%)$, bla $_{\mathrm{NDM}}(15 \%)$ and $b l a_{\mathrm{SPM}}(2,4 \%)$ were recovered from clinical isolates. The $b l a_{\mathrm{IMP}}$ gene was not detected in any of the isolates. It is worrying that Pseudomonas aeruginosa and Acinetobacter baumannii represent the majority of isolates $(61.6 \%)$ recovered from infections at different sites, with high resistance to carbapenems, carrying simultaneously the bla $a_{\mathrm{KPC}}, b l a_{\mathrm{GES}}$ and bla $\mathrm{vIM}_{\mathrm{M}}$ genes, as well as found in Enterobactericeae. The most prevalent carbapenemase was bla $a_{\mathrm{KPC}}$ and bla $a_{\mathrm{VI}}$, followed by bla $a_{\mathrm{NDM}}$ among the resistant multidrug isolates. These results are a threat to public health, configuring high rates of resistance, limiting therapeutic options.
\end{abstract}

Keywords: Gram-negative bactéria; Carbapenemase; Resistant multidrug; Molecular epidemiology. 


\begin{abstract}
Resumen
La resistencia a las carbapenemasas en los bacilos gram-negativos (BGN) se ha convertido en un problema mundial, aumentando la tasa de morbilidad y mortalidad. Se utilizó el método automatizado para la identificación y susceptibilidad de los aislamientos. Y el método molecular se aplicó en la detección de bacilos gram-negativos (BGN) productores de carbapenemasa. Se recuperó un total de 205 BGN de diferentes muestras clínicas resistentes a las carbapenemasas. Los genes de resistencia bla $a_{\mathrm{KPC}}(57,5 \%)$, bla $a_{\mathrm{VIM}}(30,2 \%), b l a_{\mathrm{GES}}(17 \%)$, bla $_{\mathrm{NDM}}(15 \%)$ у $b l a_{\mathrm{SPM}}$ $(2,4 \%)$ se recuperaron de los aislados clínicos. El gen bla IMP no se detectó en ninguno de los aislamientos. Es preocupante que Pseudomonas aeruginosa y Acinetobacter baumannii representen la mayoría de los aislamientos $(61,6 \%)$ recuperados de infecciones en diferentes sitios, con alta resistencia a los carbapenémicos, que portan simultáneamente los genes $b l a_{\mathrm{KPC}}$, bla $_{\mathrm{GES}}$ y bla $a_{\mathrm{VIM}}$, así como los encontrados en Enterobactericeae. La carbapenemasa más prevalente fue $b l a_{\mathrm{KPC}}$ y $b l a_{\mathrm{VIM}}$, seguida de $b l a_{\mathrm{NDM}}$ entre los aislados de múltiples fármacos resistentes. Estos resultados son una amenaza para la salud pública, configurando altas tasas de resistencia, limitando las opciones terapéuticas.
\end{abstract}

Palabras clave: Bacterias gram-negativas; Carbapenemasa; Multifármaco resistente; Epidemiología molecular.

\title{
1. Introdução
}

Infecções por bacilos gram-negativos produtores de carbapenemases surgiram como uma grande ameaça e está associada a altas taxas de mortalidade (Nordmann, Poirel, 2019; Wilson, Török, 2018).

A prevalência da produção de carbapenemase apesar de estar disseminada mundialmente, essa distribuição varia de acordo com as regiões do mundo. A resistência a carbapenemase em bactérias não fermentadoras incluindo Pseudomonas aeruginosa e Acinetobacter baumannii embora menos freqüente, apresenta uma ameaça mundial na Alemanha (Hagemann et al, 2018), na Estônia (Telling et al, 2018), na Bulgaria (Petrova et al, 2017), na América Latina (Labarca et al, 2016) representando um desafio emergente para a saúde pública agentes terapêuticos ativos contra esses patógenos.

Além disso, a resistência a carbapenemase em Enterobacteriales se espalha rapidamente tornando-se endêmicos em alguns países como na Tunísia que chega a 81,6\% (Ben Helal et al, 2018), no norte da Califórnia (38,7\%) (Senchyna et al, 2019), na China (89\%) (Zhang et al, 2018) e Egito (33,8\%) (Soliman et al, 2020), assim como também é observado na America Latina incluindo Brasil, Colômbia, Argentina e México (Escandón-Vargas et al, 2017). Geralmente essas infecções causadas por Enterobacteriales produtora de carbapenemase são mais comuns no trato urinário, na corrente sanguínea e infecções do trato respiratório (Oteo et al, 2013). E os antibióticos comumente usados no tratamento são geralmente inativos contra CPE.

Os principais grupos de carbapenemase mais comumente encontrados incluem KPC, NDM e OXA-48 (Iovleva; Doi, 2017), limitando desta forma as opções terapêuticas. A rápida expansão da resistência adquirida aos carbapenemes é cada vez mais propagada por elementos genéticos móveis, como plasmídeos que transferem genes de carbapenemase intra e entre as BGN (Brink, 2019). Os genes da $\beta$-lactamase carregados em elementos genéticos móveis são importantes para a rápida disseminação de BGN resistentes à antibióticos em todo o mundo (Logan; Weinstein, 2017). As carbapenemases VIM, NDM, KPC, OXA-48 e IMP são as mais comumente encontradas em centros de saúde incluindo, Grécia, Guatemala, Itália, Espanha, Sérvia e Vietnã (Peirano et al, 2018). Diante disso, o objetivo desse estudo foi analisar a epidemiologia molecular de bacilos Gram-negativos multidrogas resistente produtores de carbapenemases isoladas de diferentes sítios de infecção em um hospital de referencia do Estado de Pernambuco, Brasil.

\section{Metodologia}

Trata-se de um estudo observacional, no qual os bacilos gram-negativos foram isolados de amostras de diferentes sítios de infecção de pacientes de várias unidades do hospital público de referência do Estado de Pernambuco. Foram recuperados 205 isolados por demanda espontânea, no qual foram isolados e identificados bioquimicamente quanto a espécie bacteriana e perfil de resistência a antimicrobianos em sistema automatizado VITEK 2 (BIOMERIEUX®). Os isolados foram 
mantidos em estoque congelado com glicerol $15 \%$ a $-80^{\circ} \mathrm{C}$ para realização das análises moleculares.

\section{Análise molecular}

O DNA bacteriano foi extraído através de kit de Extração de DNA da Promega®®. Uma colônia pura de cada isolado foram incubados durante $24 \mathrm{~h}$ a $37^{\circ} \mathrm{C}$ em ágar MacConkey (Merck KgaA, Darmstadt, Alemanha) suspensa em $200 \mu \mathrm{L}$ de TrisEDTA pH 8,0. A suspensão foi centrifugada a 13.000 rotações por minuto durante 2 minutos, a suspensão foi descartada e a partir do pellet foi realizado a extração de DNA de acordo com o protocolo do fabricante. A qualidade do DNA foi avaliada usando o espectrofotômetro NanoDrop TM 2000 (ThemoFisher Scientific, Wilmington, Delaware, EUA).

\section{Detecção de Carbapenemases em BGN}

Todos os isolados resistentes ao carbapenem foram rastreados por PCR para os genes bla $a_{\mathrm{KPC}}$, bla $_{\mathrm{NDM}}$, bla $_{\mathrm{GES}}$, bla $_{\mathrm{IMP}}$, blas $_{\mathrm{PM}}$, bla $_{\mathrm{VIM}}$, bla $_{\mathrm{OXA}-48-\text {-like }}$ usando iniciadores e condições específicos listados em tabela 2.

\section{Condições da PCR para identificação dos genes bla ${ }_{\mathrm{KPC}}$ e $b l a_{\mathrm{GES}}$}

Os genes de resistência bla $a_{\mathrm{KPC}}$ e $b l a_{\mathrm{GES}}$ foram investigados utilizando os primers 5'ATGTCACTGTATCGCCGTCTAGTTC -3' e 5'- CAATCCCTCGAGCGCGAGTC -3' para detecção de bla $a_{\mathrm{KPC}}$. E os primers

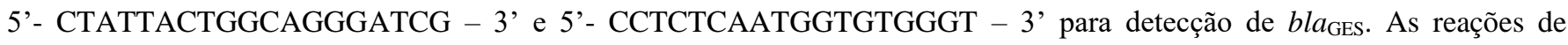
amplificação foram preparadas em um volume total de $25 \mu \mathrm{l}$ por tubo, compreendendo: $1 \mu 1$ de DNA genômico a 5ng/ $\mu 1,2,0 \mathrm{U}$ da enzima Taq DNA polimerase (Promega), $200 \mu \mathrm{M}$ de dNTP (Ludwig Biotec), 1,5 mM de MgCl2 e $1 \mu \mathrm{mol}$ dos primers. Em cada partida de amplificação foi incluso um controle negativo e um controle positivo. As amplificações do gene bla $a_{\mathrm{KPC}}$ foram realizadas com ciclos de desnaturação inicial à $95^{\circ} \mathrm{C}$ por 5 minutos, seguido de 30 ciclos, consistindo cada ciclo de 1 minuto à $95^{\circ} \mathrm{C}$ para desnaturação, 1 minuto à $63^{\circ} \mathrm{C}$ para anelamento do primer e 1 minuto à $72^{\circ} \mathrm{C}$ para extensão. Após estes ciclos foi realizada uma etapa de alongamento final de 10 minutos à $72{ }^{\circ} \mathrm{C}$. A amplificação do gene bla $a_{\mathrm{GES}}$ utilizou as seguintes condições: 3 min a $93^{\circ} \mathrm{C}$ para desnaturação inicial; seguido de 40 ciclos de $1 \min$ à $93^{\circ} \mathrm{C}, 1$ min à $55^{\circ} \mathrm{C}$ e 1 min à $72^{\circ} \mathrm{C}$, e 7 $\min$ à $72^{\circ} \mathrm{C}$ para extensão final (Wang et al, 2006).

\section{Condições da PCR para identificação dos genes bla $_{\mathrm{NDM}}$, bla $_{\mathrm{IMP}}$, bla $_{\mathrm{SPM}}$, bla $_{\mathrm{VIM}}$}

Os genes de resistência $b l a_{\mathrm{VIM}}, b l a_{\mathrm{IMP}}$ foram investigados pela técnica de PCR, com os primers descritos por Mendes, 2007. As reações de amplificação foram preparadas em um volume total de $25 \mu 1$ por tubo, compreendendo: $1 \mu 1$ de DNA genômico a 20ng/ $\mu 1,1,0 \mathrm{U}$ da enzima Taq DNA polimerase (Promega), $100 \mu \mathrm{M}$ de dNTP (Ludwig Biotec), 1,5 mM de MgCl2 e $0,4 \mu \mathrm{mol}$ dos primers. Em cada partida de amplificação foi incluso um controle negativo e um controle positivo. As amplificações dos genes de MBL foram realizadas com ciclos de desnaturação inicial à $95^{\circ} \mathrm{C}$ por 5 minutos, seguido de 30 ciclos, consistindo cada ciclo de 1 minuto à $95^{\circ} \mathrm{C}$ para desnaturação, para anelamento dos primers: 1 minuto à $60^{\circ} \mathrm{C}$ para $b l a_{\mathrm{IMP}}$ e blaspm (Mendes, 2007) e 1 minuto à $620 \mathrm{C}$ para bla VIM $_{\text {IM }}$ e para extensão, 1 minuto à $68^{\circ} \mathrm{C}$. Após estes ciclos foi realizado uma etapa de alongamento final de 5 minutos à $68^{\circ} \mathrm{C}$.

A presença do gene bla $a_{\mathrm{NDM}}$ foi investigada utilizando os primers descritos na literatura (Nordmann et al., 2011). As reações de amplificação foram preparadas em um volume total de $50 \mu 1$ por tubo, compreendendo: $2 \mu 1$ de DNA genômico, 2,0U da enzima Taq DNA polimerase (Promega), 0,125 mM de cada dNTP, 1,5 $\mathrm{mM}$ de $\mathrm{MgCl} 2$ e 0,1 $\mu$ mol dos primers. A amplificação foi realizada sob as seguintes condições térmicas de ciclagem: 10 min à $94^{\circ} \mathrm{C}$ para desnaturação inicial, 36 ciclos de amplificação consistindo em 30s à $94^{\circ} \mathrm{C}, 40$ s à $52^{\circ} \mathrm{C}, 50$ s à $72^{\circ} \mathrm{C}$ e para a extensão final 5 min à $72^{\circ} \mathrm{C}$. 


\section{Condições da PCR para identificação dos genes blaoxa-48}

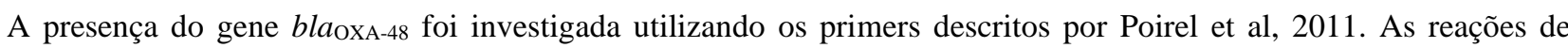
amplificação foram preparadas em um volume total de $25 \mu 1$ por tubo, compreendendo: $1 \mu 1$ de DNA genômico, 1,0U da enzima Taq DNA polimerase (Promega), $2 \mathrm{mM}$ de cada dNTP, 2,5 $\mathrm{mM}$ de $\mathrm{MgCl}_{2}$ e 3,5 pmol dos primers. A amplificação foi realizada sob as seguintes condições térmicas de ciclagem: 5 min à $94^{\circ} \mathrm{C}$ para desnaturação inicial, 35 ciclos de amplificação consistindo em 60 s à $94^{\circ} \mathrm{C}, 45 \mathrm{~s}$ à $55^{\circ} \mathrm{C}, 60$ s à $72^{\circ} \mathrm{C}$ e para a extensão final 7 min à $72^{\circ} \mathrm{C}$.

\section{Considerações Éticas}

Este estudo foi aprovado pelo comitê de ética (CAAE: 20195119.3.0000.5586) número de perecer 3.787.364 e (CAAE: 20195119.3.3001.5198) número de parecer 3.838.892, seguindo a Resolução 466/12 do Conselho Nacional de Saúde.

\section{Resultados}

Um total de 205 bacilos Gram-negativos foram isoladas de diferentes sítios de infecções de pacientes atendidos em hospital de referência no estado de Pernambuco, Brasil. Do total de 205 isolados, a maioria foram de amostra de secreção traqueal $52(25,37 \%)$, seguida de amostras de urina $48(23,9 \%)$, liquor $17(8,3 \%)$, ponta de cateter $12(5,8 \%)$, swab retal 12 $(5,8 \%)$ e swab nasal 10 (4,8\%), ferida operatória 15 (7,31\%), hemocultura 14 (6,8\%), liquído peritoneal 5 (2,4\%), liquído pleural $2(1 \%)$, abscesso $4(2 \%)$, osso $3(1,5 \%)$, partes moles $2(1 \%)$, outros fluidos corporais 8 (4\%). Entre 205 isolados, 76 (37\%) foram A. baumanii, 51 (25\%) P. aeruginosa, 25 (12,7\%) Proteus spp, 20 (9,75\%) K. pneumoniae, 18 (8,8\%) Serratia marcescens, 7 (3,4\%) Providencia stuarti, 2 (1\%) E. coli, 2 (1\%) Klebsiella aerogenes, 1 (0,5\%) Enterobacter cloacae, 1 (0,5\%) Morganella morganii, e 1 (0,5\%) Burkholderia cepacia (Gráfico 1).

Gráfico 1. Distribuição dos isolados bacterianos Gram-negativos multidroga resistentes isolados de diferentes sítios de infecção.

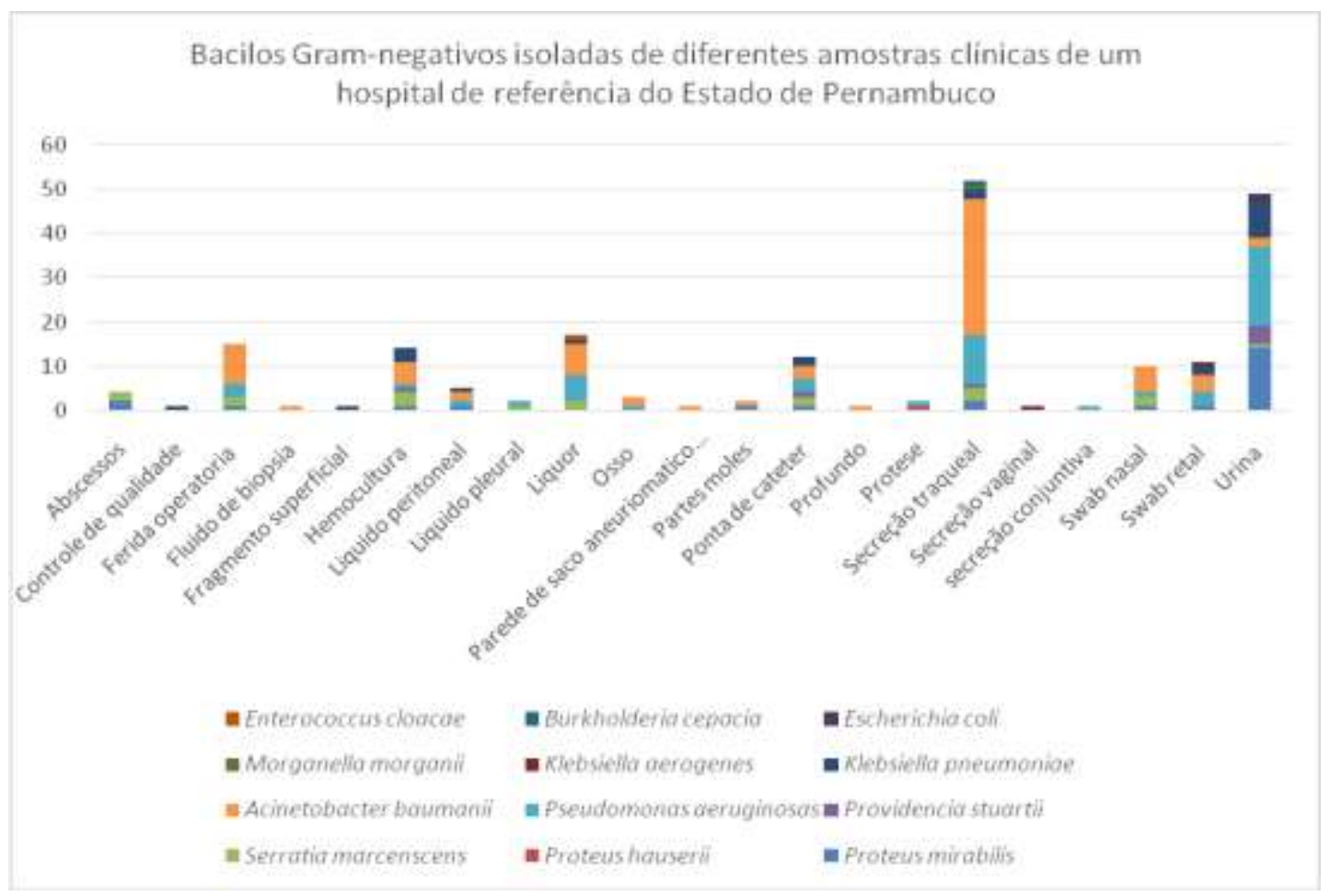

Fonte: Autores. 


\section{Perfil de Suscetibilidade Antimicrobiana}

Todos os isolados gram-negativos multidroga resistente (MDR) foram analisados de acordo com a definição do ponto de corte clínico BrCAST versão 10.0 (www.brcast.org.br). Dos isolados de Proteus mirabilis, 17 foram produtores de bla $a_{\mathrm{NDM}} \mathrm{e}$ 11 de bla $a_{\mathrm{KPC}}$, apresentando maior resistência à aminoglicosideos, betalactâmico, cefalosporinas de $2^{\mathrm{a}}, 3^{\mathrm{a}}$ e $4^{\mathrm{a}}$ geração e fluoroquinolonas. A resistência intrínseca à colistina e polimixina B foi observada principalmente em Proteus spp, Serratia mascescens, Providencia stuartii e Klebsiella spp.

Alto nível de resistência foi observado em cefalosrorinas (cefazolina, cefuroxima, cefuroxima axetil, cefepima, cefoxitina, ceftazidima e ceftriaxona).

O perfil de suscetibilidade aos antibióticos mostrou que os isolados eram mais resistentes à cefazolina $(99,38 \%)$, cefuroxima (98,5\%), cefuroxima/axetil (97,4\%), ticarciclina/Ácido clavulanico $(97,1 \%)$, imepenem $(96,5 \%)$, ceftriaxona $(95,6 \%)$, aztreonam $(95,3 \%)$, meropenem $(94,14 \%)$, ampicilina/subactam $(94,1 \%)$, ceftazidima $(92,2 \%)$, cefepima $(89,1 \%)$, cefoxitina $(87 \%)$ ertapenem $(84,41 \%)$, e eram menos resistentes à ciprofloxacina $(73,5 \%)$, levofoxacina (70\%), ampicilina $(56 \%)$, gentamicina $(41,11 \%)$ e amicacina $(33,3 \%)$ Tabela 1.

Tabela 1. Perfil de suscetibilidade antimicrobiana de isolados bacterianos de diferentes sítios de infecção.

\begin{tabular}{lllll}
\hline Antimicrobianos & $\mathbf{n}^{\mathbf{0}} \mathbf{d e}$ isolados & $\mathbf{n}^{\mathbf{0}}$ Suscetível (\%) & $\mathbf{n}^{\mathbf{0}}$ Intermediário (\%) & $\mathbf{n}^{\mathbf{0}}$ Resistente $(\boldsymbol{\%})$ \\
\hline Amicacina & 204 & $114(55,8 \%)$ & $22(10,8 \%)$ & $68(33,3 \%)$ \\
\hline Ampicilina & 58 & $2(3,44 \%)$ & $0(0,0)$ & $56(\%)$ \\
\hline Ampicilina/Sulbactam & 153 & $8(5,22 \%)$ & $1(0,65 \%)$ & $144(94,1 \%)$ \\
\hline Aztreonam & 43 & $2(4,65 \%)$ & $0(0,0)$ & $41(95,3 \%)$ \\
\hline Cefepima & 203 & $19(9,35 \%)$ & $3(1,47 \%)$ & $181(89,1 \%)$ \\
\hline Cefazolina & 162 & $1(0,61 \%)$ & $0(0,0)$ & $161(99,38 \%)$ \\
\hline Cefoxitina & 62 & $5(8,06 \%)$ & $3(4,83 \%)$ & $54(87,09 \%)$ \\
\hline Ceftazidima & 205 & $14(6,82 \%)$ & $2(0,97 \%)$ & $189(92,2 \%)$ \\
\hline Ceftriaxona & 205 & $6(2,92 \%)$ & $3(1,46 \%)$ & $196(95,6 \%)$ \\
\hline Cefuroxima & 204 & $3(1,47 \%)$ & $0(0,0)$ & $201(98,5 \%)$ \\
\hline Cefuroxima Axetil & 77 & $2(2,6 \%)$ & $0(0,0)$ & $150(73,5 \%)$ \\
\hline Ciprofloxacina & 204 & $42(20,6 \%)$ & $12(5,88 \%)$ & $65(84,41 \%)$ \\
\hline Ertapenem & 77 & $12(15,58 \%)$ & $0(0,0)$ & $90(44,11 \%)$ \\
\hline Gentamicina & 204 & $107(52,45 \%)$ & $7(3,43 \%)$ & $197(96,5 \%)$ \\
\hline Imepenem & 204 & $4(1,96 \%)$ & $3(1,47 \%)$ & $193(94,14 \%)$ \\
\hline Meropenem & 205 & $12(5,85 \%)$ & $0(0,0)$ & $79(70 \%)$ \\
\hline Levofloxacina & 113 & $34(30,1 \%)$ & $0(0,0)$ & $137(97,1 \%)$ \\
\hline Ticarciclina/Ácido & 141 & $4(2,83 \%)$ & $0(0,0)$ & $31(57,40 \%)$ \\
clavulanico & & & & $9(75 \%)$ \\
\hline Tobramicina & 54 & $23(42,6 \%)$ & $0(0,0)$ & $0(0,0)$ \\
\hline Norfloxacina & 12 & $3(25 \%)$ & $0(0,0)$ & $7(5,83 \%)$ \\
\hline Pipe/Tazobatam & 9 & $9(100 \%)$ & $0(0,0)$ & $16(11 \%)$ \\
\hline Tigeciclina & 120 & $96(80 \%)$ & $17(14,16 \%)$ & $16(11,18 \%)$ \\
\hline Colistina & 146 & $130(89 \%)$ & $0(0,0)$ & $0(0,0)$ \\
\hline Polimicina B & 143 & $127(88,8 \%)$ & & \\
\hline
\end{tabular}

Nem todos os antibióticos foram testados para todos os 205 isolados e nem todos os valores de $\mathrm{n}$ somaram 205. Fonte: Autores.

\section{Bactérias gram-negativas resistentes a carbapenemases}

Dos 205 isolados que apresentaram resistência fenotípica a imipenem e meropenem, 166 (80,9\%) foram positivos para a produção de carbapenemase pela detecção de genes de resistência. Os organismos mais frequentes produtores de carbapenemase foram Proteus spp 23 (88\%), Serratia mascescens 18 (100\%) e Pseudomonas aeruginosa 46 (90\%) (Tabela 2). Os resultados da PCR revelam que o gene bla $a_{\mathrm{KPC}}$ foi observado em 11 espécies de Proteus mirabilis, 16 Serratia mascescens, 4 Providencia stuartii, 44 Pseudomonas aeruginosa, 22 Acinetobacter baumannii, 16 Klebsiella spp., 1 Morganella morganii, 2

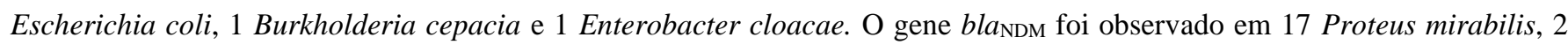


Research, Society and Development, v. 10, n. 9, e30210918070, 2021

(CC BY 4.0) | ISSN 2525-3409 | DOI: http://dx.doi.org/10.33448/rsd-v10i9.18070

Serratia mascescens, 2 Providencia stuartii, 4 Pseudomonas aeruginosa, 1 Acinetobacter baumannii, 5 Klebsiella spp.

A presença de bla $a_{\mathrm{GES}}$ foi constatada em 5 Proteus mirabilis, 16 Serratia mascescens, 1 Providencia stuartii, 6 Pseudomonas aeruginosa, 4 Acinetobacter baumannii, 1 Klebsiella pneusmoniae, 1 Escherichia coli e 1 Enterobacter cloacae.

A produção do gene bla $a_{\mathrm{VIM}}$ foi observada em 20 Pseudomonas aeruginosa, 37 Acinetobacter baumannii, 5 Klebsiella pneumoniae. Apenas 4 isolados de $P$. aeruginosas e $1 \mathrm{~K}$. aerogenes foram positivos para o gene blaspM. Um isolado apresentou

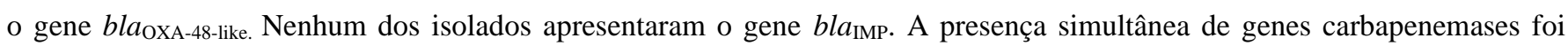
detectada em alguns isolados. 


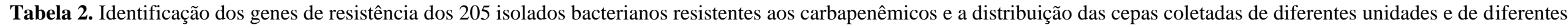
sítios em um hospital público de referência de Pernambuco, Brasil.

\begin{tabular}{|c|c|c|c|c|}
\hline Isolado bacteriano (n) & Amostra coletada & Unidade & Genes (n) \% & Resistência Antimicrobiana $\left(\mathbf{n}^{0}\right)$ \\
\hline Proteus mirabilis (25) & $\begin{array}{l}\text { Abscesso (2) } \\
\text { Ferida operatória (1) } \\
\text { Hemocultura (1) } \\
\text { Ponta de cateter (1) } \\
\text { Secreção traqueal (2) } \\
\text { Partes moles (1) } \\
\text { Urina (14) } \\
\text { Swab nasal (1) } \\
\text { Swab retal (1) } \\
\text { Liquido peritoneal (1) }\end{array}$ & $\begin{array}{l}\text { Enfermaria (13) } \\
\text { UTI (8) } \\
\text { SRPA (1) } \\
\text { USAN (1) } \\
\text { Und de Trauma (1) } \\
\text { Neurocirurgia (1) }\end{array}$ & $\begin{array}{l}\text { KPC (11) } 45,8 \% \\
\text { NDM (18) } 70,8 \% \\
\text { GES (5) } 20 \%\end{array}$ & $\begin{array}{l}\text { AMI (4), AMP (24), ASB (23) } \\
\text { ATM (23), CPM (23), CFO (23) } \\
\text { CAZ (23), CRO (23), CRX (23) } \\
\text { Cefuroxima Axetil (23), CIP (8), Ertapenem } \\
\text { (20), GEN (2), IPM (24), LVX (11), MER } \\
\text { (21), TIC (23), TOB (11) }\end{array}$ \\
\hline Proteus hauseri (1) & Secreção de prótese (1) & Enfermaria (1) & - & $\begin{array}{l}\text { AMP, CFZ, CRX, Cefuroxima Axetil, CIP, } \\
\text { IPM, LVX }\end{array}$ \\
\hline Providencia stuartii (7) & $\begin{array}{l}\text { Urina (4) } \\
\text { Hemocultura (1) } \\
\text { Ponta de cateter (1) } \\
\text { Secreção traqueal (1) }\end{array}$ & $\begin{array}{l}\text { UTI (3) } \\
\text { UTQ (1) } \\
\text { UCEN (1) } \\
\text { Enfermaria (1) } \\
\text { Sala de recuperação (1) }\end{array}$ & $\begin{array}{l}\text { KPC (4) } 57,14 \% \\
\text { NDM (2) } 28,6 \% \\
\text { GES (1) } 14,28 \% \\
\text { OXA-48 (1) } 14,28 \%\end{array}$ & $\begin{array}{l}\text { AMI (1), AMP (7), ASB (7), CPM (3), CFO } \\
\text { (4), CAZ (6), CRO (7), CRX (7), } \\
\text { Cefuroxima Axetil (7), CIP (1), Ertapenem } \\
\text { (5), GEN (5), IPM (7), LVX (1), MER (5), } \\
\text { TOB (1) }\end{array}$ \\
\hline Serratia marcescens (18) & $\begin{array}{l}\text { Abscesso (2) } \\
\text { Ferida operatória (2) } \\
\text { Liquido peritoneal (1) } \\
\text { Liquido pleural (1) } \\
\text { Secreção traqueal (3) } \\
\text { Hemocultura (3) } \\
\text { Ponta de cateter (2) } \\
\text { Swab nasal (2) } \\
\text { Liquor (2) } \\
\text { Urina (1) }\end{array}$ & $\begin{array}{l}\text { Enfermaria (8) } \\
\text { UTI (7) } \\
\text { Neurocirurgia (3) } \\
\text { USAN (1) }\end{array}$ & $\begin{array}{l}\text { KPC (16) } 88,88 \% \\
\text { NDM (2) } 11,1 \% \\
\text { GES (17) } 94,4 \%\end{array}$ & $\begin{array}{l}\text { AMI (8), AMP (18), ASB (18), ATM (18), } \\
\text { CPM (17), CFO (18), CAZ (18), CRO (18), } \\
\text { CRX (18), Cefuroxima Axetil (18), CIP (7), } \\
\text { Ertapenem (18), GEN (6), IPM (18), LVX } \\
\text { (8), MER (18), TIC (18), TOB (17), TIG (1) }\end{array}$ \\
\hline Pseudomonas aeruginosa (51) & $\begin{array}{l}\text { Osso (1) } \\
\text { Ferida operatória (3) } \\
\text { Secreção traqueal (11) } \\
\text { Secreção conjuntival (1) } \\
\text { Liquor (6) } \\
\text { Hemocultura (1) } \\
\text { Ponta de cateter (3) } \\
\text { Urina (18) } \\
\text { Swab nasal (1) } \\
\text { Swab retal (3) } \\
\text { Liquido peritoneal (1) } \\
\text { Liquido pleural (1) } \\
\text { Protese (1) }\end{array}$ & $\begin{array}{l}\text { Enfermaria (21) } \\
\text { UTI (23) } \\
\text { UTIP (2) } \\
\text { SR (1) } \\
\text { Und de trauma (1) } \\
\text { UCEN (2) } \\
\text { USAN (1) }\end{array}$ & $\begin{array}{l}\text { KPC (44) } 86,27 \% \\
\text { NDM (4) } 7,84 \% \\
\text { GES (6) } 11,8 \%\end{array}$ & $\begin{array}{l}\text { AMI (39), CFZ (51), CAZ (47), CRO (51), } \\
\text { CRX (51), GEN (44), IPM (50), LVX (47), } \\
\text { MER (50) }\end{array}$ \\
\hline Acinetobacter baumanii (76) & $\begin{array}{l}\text { Secreção traqueal (31) } \\
\text { Fluido de biopsia (1) } \\
\text { Ferida operatória (9) }\end{array}$ & $\begin{array}{l}\text { Enfermaria (19) } \\
\text { UTI (42) } \\
\text { UTIP (2) }\end{array}$ & $\begin{array}{l}\text { KPC (22) } 29 \% \\
\text { NDM (1) } 1,31 \% \\
\text { GES (4) } 5,26 \%\end{array}$ & $\begin{array}{l}\text { AMI (12), ASB (73), CPM (73), CFZ (75), } \\
\text { CAZ (73), CRO (76), CRX (76), CIP (75), } \\
\text { GEN (19), IPM (75), MER (76), }\end{array}$ \\
\hline
\end{tabular}


Research, Society and Development, v. 10, n. 9, e30210918070, 2021

(CC BY 4.0) | ISSN 2525-3409 | DOI: http://dx.doi.org/10.33448/rsd-v10i9.18070

\begin{tabular}{|c|c|c|c|c|}
\hline & $\begin{array}{l}\text { Swab nasal (6) } \\
\text { Swab retal (5) } \\
\text { Liquor (7) } \\
\text { Liquido peritoneal (2) } \\
\text { Hemocultura (5) } \\
\text { Ponta de cateter (3) } \\
\text { Osso (2) } \\
\text { Partes moles (1) } \\
\text { Urina (2) } \\
\text { Parede de saco aneuriomático de orta (1) } \\
\text { Profundo (1) }\end{array}$ & $\begin{array}{l}\text { UTQ (2) } \\
\text { UCEN (2) } \\
\text { SR (6) } \\
\text { Neurocirurgia (3) }\end{array}$ & & Ticarciclina/Ác clavulanico (76) \\
\hline Klebsiella pneumoniae (20) & $\begin{array}{l}\text { Liquor (1) } \\
\text { Ponta de cateter (2) } \\
\text { Hemocultura (3) } \\
\text { Urina (7) } \\
\text { Secreção traqueal (2) } \\
\text { Liquido peritoneal (1) } \\
\text { Fragmento superficial (1) } \\
\text { Swab retal (2) } \\
\text { Controle de qualidade (1) }\end{array}$ & $\begin{array}{l}\text { Enfermaria (6) } \\
\text { UTI (10) } \\
\text { UCEN (2) } \\
\text { Sala de recuperação (1) } \\
\text { Não informado (1) }\end{array}$ & $\begin{array}{l}\text { KPC (16) } 80 \% \\
\text { NDM (4) 20\% } \\
\text { GES (1) } 5 \%\end{array}$ & $\begin{array}{l}\text { AMI (2), ASB (20), CPM (18), CFO (15), } \\
\text { CAZ (20), CRO (20), CRX (20), } \\
\text { Cefuroxima Axetil (20), CIP (12), } \\
\text { Ertapenem (19), GEN (10), IPM (19), LVX } \\
\text { (13), MER (19), Ticarciclina/Ác clavulanico } \\
\text { (19) }\end{array}$ \\
\hline Klebsiella aerogenes (2) & $\begin{array}{l}\text { Secreção vaginal (1) } \\
\text { Swab retal (1) }\end{array}$ & $\begin{array}{l}\text { UTI (1) } \\
\text { Enfermaria (1) }\end{array}$ & $\begin{array}{l}\text { KPC (1) 50\% } \\
\text { NDM (1) } 50 \%\end{array}$ & $\begin{array}{l}\text { AMP (2), ASB (2), CPM (2), CFO (2), CAZ } \\
\text { (2), CRO (2), CRX (2) } \\
\text { Cefuroxima Axetil (2), CIP (1), Ertapenem } \\
\text { (2), IPM (2), LVX (1), MER (2), TIC (1) }\end{array}$ \\
\hline Morganela morgani (1) & Secreção traqueal (1) & UTI (1) & KPC (1) $100 \%$ & AMP, CFZ, CRX, Cefuroxima Axetil, \\
\hline Escherichia coli (2) & Urina (2) & USAN (2) & $\begin{array}{l}\text { KPC (2) } 100 \% \\
\text { GES (1) } 50 \%\end{array}$ & $\begin{array}{l}\text { AMP (2), ASB (2), CPM (1), CFZ (2), CFO } \\
\text { (2), CAZ (2), CRO (2), CRX (2), } \\
\text { Cefuroxima Axetil (2), Ertapenem (2), GEN } \\
\text { (2), IPM (2), MER (2), Ticarciclina/Ác } \\
\text { clavulanico (2) }\end{array}$ \\
\hline Bucoderia cepacia (1) & Secreção traqueal (1) & USAN (1) & KPC (1) $100 \%$ & $\mathrm{CRO}(1)$ \\
\hline Enterbacter cloaceae (1) & Liquor (1) & Enfermaria (1) & $\begin{array}{l}\text { KPC (1) } 100 \% \\
\text { GES (1) } 100 \%\end{array}$ & $\begin{array}{l}\text { AMP, CFO, CRX, Cefuroxima Axetil, IPM, } \\
\text { MER, }\end{array}$ \\
\hline
\end{tabular}

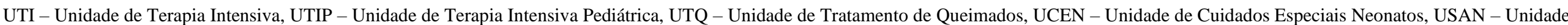
de Serviço em Atendimento Neurológico, SR - Sala de Recuperação, SRPA - Sala de Recuperação Pós-Anestésica. Fonte: Autores. 


\section{Discussão}

Infecções relacionadas a bacilos Gram-negativos multidroga resistentes, especialmente a carbapememases estão se tornando cada vez mais freqüentes, tornando uma ameaça à saúde pública, limitando cada vez mais as opções terapêuticas. No presente estudo a maioria dos isolados foram recuperados de secreção traqueal $52(25,3 \%)$ e urina $49(24 \%)$. Sendo a maioria dos isolados predominante de UTI (100) e enfermaria (70), 170 (82,9\%).

Um estudo de Gana mostrou maior frequiência de infecções em amostras de urina (34,5\%), sepse (14,5\%), secreção de ferida (11\%) resistentes a múltiplos medicamentos (Agyepong et al, 2018).

O perfil de suscetibilidade antimicrobiana dos isolados apresentou alto nível de resistência à cefazolina, cefuroxima, ticarciclina/ácido clavulanico, imepenem, meropenem, observado em outros estudos como na Índia (Mohapatra et al, 2018), no México (Uc-Cachón et al, 2019). Em contrapartida, outro estudo mostrou perfil de resistência mais freqüente em aminoglicosideo e fluoroquinolonas (Zeynudin et al, 2018).

As bactérias não fermentadoras 127 (61,9\%) representam a maioria, sendo 51 Pseudomonas aeruginosa e 76 Acinetobacter baumannii, destes apresentam pelo menos um gene de resistência a carbapenemase em P. aeruginosa (49) e em A. baumannii (42).

Em nosso estudo a produção de carbapenemase foi de 80,9\% (166), com altas taxas entre Serratia marcescens e Klebsiella spp (100\%), Pseudomonas aeruginosa (96\%) e Proteus spp. (88,5\%). Dados semelhantes foram observados de resistentes a carbapenemase (74,5\%) em BGN, com altas taxas entre A. baumannii (89\%) e K. pneumoniae (78\%). As maiores taxas de resistência foram encontradas em agentes penicilinas e cefalosporinas, realizadas por triagem fenotípica em um estudo no Sudão (Dirar et al, 2020).

Dentre 127 bacilos Gram-negativos não fermentadores resistentes a carbapenêmicos 91 (71,6\%) produziram carbapenemases. Resultados semelhantes foram observados em estudos recentes, no qual um total de $86 \%$ dos isolados de $P$. aeruginosa produtores de carbapenemase produziram carbapenemases classe B. E que $60 \%$ dos isolados de A. baumannii produtores de carbapenemase classe D produzem carbapenemases do tipo OXA (Simmer et al, 2017). Além disso, os genes de metalo- $\beta$-lactamase (NDM) carbapenemase de Nova Delhi foram detectados em $92 \%$ entre as enterobactérias (Dretler et al, 2020). No presente estudo foi encontrado uma porcentagem relativamente baixa de detecção de carbapenemases dos tipos NDM, SPM e IMP, o que tem sido comumente relatado em outros estudos no Brasil (Carvalho-Assef, et al, 2013, Ferreira et al, 2016 e Firmo et al, 2019).

Os resultados revelaram que $b l a_{\mathrm{KPC}}$ foi o mais prevalente 118 (57,5\%), seguido por bla $a_{\mathrm{VIM}} 62(30,2 \%)$, depois $b l a_{\mathrm{GES}}$ $35(17 \%), b_{\mathrm{NDM}} 31(15 \%)$ e bla SPM $_{5} 5(2,4 \%)$. Curiosamente, alguns isolados abrigavam mais de um tipo de metaloßetalactamase. Seis isolados de Proteus mirabilis abrigavam bla $_{\mathrm{KPC}}$, bla $a_{\mathrm{NDM}}$, e três destes isolados também abrigavam o gene bla $a_{\mathrm{GES}}$. Embora, o gene bla $a_{\mathrm{KPC}}$ tenha sido identificado em isolados de Klebsiella spp desde então, já foram documentadas nas Americas (Castanheira et al, 2020, Cuaical-Ramos et al, 2019) incluindo o Brasil (Firmo et al, 2020, Araújo et al, 2018). A carbapenemase bla $a_{\mathrm{VIM}}$ foi predominante, seguida de bla $a_{\mathrm{KPC}}$ e $b l a_{\mathrm{NDM}}$ em infecção da corrente sanguinea em um estudo Grego (Papadimitriou-Olivgeris et al, 2019), diferentemente do nosso estudo, o qual mostrou uma predominância de 57,5\% (118/205) entre $b l a_{\mathrm{KPC}}$.

O gene bla $a_{\mathrm{VIM}}$ foi relatado como o segundo gene mais prevalente com $30,2 \%$ entre os isolados Pseudomonas aeruginosa, Acinetobacter baumannii e Klebsiella pneumoniae. O gene bla $\mathrm{VIIM}_{-4}$ já foi encontrado em isolados de $P$. aeruginosa produtoras de metallo $\beta$-lactamases (Merradi et al, 2019). Isolados de P. aeruginosa (20) que carregavam simultaneamente os genes bla $a_{\mathrm{KPC}}$ e bla $a_{\mathrm{VIM}} \mathrm{MDR}$, suscetíveis apenas à colistina, conforme já relatado em estudos (Pacheco et al, 2019). Girija e colaboradores (2018) mostraram uma detecção de bla $a_{\mathrm{VIM}} \mathrm{em} 34,24 \%$ em isolados de A. baumanii de infecção do trato urinário, não apresentando genes $b l a_{\mathrm{IMP}}$ e bla $a_{\mathrm{NDM}}$. Em nosso estudo o gene bla $a_{\mathrm{NDM}}$ foi documentado em Proteus 
mirabilis, Serratia mascescens, Providencia stuartii, Pseudomonas aeruginosa, Acinetobacter baumanii, Klebsiella pneumoniae e Klebsiella aerogenes. Na China o gene bla $a_{\mathrm{NDM}-5}$ foram identificados em cepas de Klebsiella pneumoniae, Klebsiella aerogenes e Escherichia coli, apresentaram resistência significativamente alta aos antibióticos $\beta$-lactâmicos, sendo suscetíveis à tigeciclina e colistina. As estirpes de $K$. pneumoniae e $K$. aerogenes foram respectivamente definidas como isolados clonais homólogos por electroforese em gel de campo pulsado (PFGE) (Tian et al, 2020). O gene bla OXA-48-like foi detectado em apenas um isoldado de Providencia stuartii. Relatado anteriormente no Nepal (Sah et al, 2019), Italia (Barbarini et al, 2015). A presença do gene bla $a_{\mathrm{IMP}}$ não foi detectada em nenhum dos isolados. Resultado semelhante encontrado no Egito (Hassuna et al, 2020). Nenhum dos isolados com resistência intrínseca à colistina abrigava gene mcr-1, similar em estudo (Lopes et al, 2020).

Os resultados mostraram uma alta taxa de resistência ao carbapenem. Apresentando isolados que abrigam mais um gene simulaneamente. Três isolados de Proteus mirabilis expressaram simultaneamente os genes $b l a_{\mathrm{KPC}}, b a_{\mathrm{NDM}}$ e $b l a_{\mathrm{GES}}$. Um isolado de Pseudomonas aeruginosa expressou os genes bla $a_{\mathrm{KPC}}$, bla VIM $_{\mathrm{IM}}$ e bla $a_{\mathrm{SPM}}$ simultaneamente. Outro isolado de $P$. aeruginosa abrigava os genes bla $a_{\mathrm{KPC}}$, bla NDM $_{\mathrm{ND}}$ bla ${ }_{\mathrm{VIM}}$. Assim como também foi encontrado em três isolados de $P$. aeruginosa os genes bla $a_{\mathrm{KPC}}$, bla $a_{\mathrm{GES}}$ e blavim simultaneamente. Em 14 isolados de Acinetobacter baumannii foram detectados simultaneamente os genes bla $a_{\mathrm{KPC}}$ e bla $a_{\mathrm{VIM}}$. Em dois isolados foram detectados os genes bla $a_{\mathrm{KPC}}$ e bla $a_{\mathrm{GES}}$. E em apenas um isolado de A. baumannii foi encontrado simultaneamente os genes bla $a_{\mathrm{KPC}}$, bla $a_{\mathrm{GES}}$ e bla $a_{\mathrm{VIM}}$.

Em um isolado de Klebsiella pneumoniae abrigava simultaneamente os genes bla $a_{\mathrm{KPC}}$, bla $a_{\mathrm{GES}}$ e bla $a_{\mathrm{VIM}}$. E em 4 isolados $K$. penumoniae expressavam os genes bla $a_{\mathrm{KPC}}$ e $b l a_{\mathrm{VIM}}$. Os genes $b a_{\mathrm{KPC}}$ e $b l a_{\mathrm{GES}}$ foram detectados simultaneamente em isolados de Escherichia coli e Enterobacter cloacea.

A coexistência simultânea de diversas $\beta$-lactamases também foram detectados no Egito (Benmahmod et al, 2019), no Iran (Kiaei et al, 2019), no Líbano (Yaghi et al, 2020).

Na China, espécie de Klebsiella pneumoniae co-abrigava os genes bla $a_{\mathrm{NDM}-1}$ e bla $a_{\mathrm{KCP}-2}$ (Yan et a, 2017). A coexistência dos genes bla $a_{\mathrm{NDM}-5}$ e bla $a_{\mathrm{OXA}-181}$ já foram identificados em um hospital terciário da Coréia em isolados de $E$ coli (Baek et al, 2019). No Brasil, culturas ativas de vigilância de pacientes de UTI de um hospital do Rio de Janeiro, co-abrigava até quatro carbapenemases NDM, KPC, OXA-48 e VIM (Flores et al, 2020). Em P. mirabilis e S. marcescens foi descrito a associação de bla $a_{\mathrm{NDM}-1}$ e bla $a_{\mathrm{KPC}-2}$ em Pernambuco, Brasil (Firmo et al, 2020). O gene bla $a_{\mathrm{NDM}}$ foi detectado em um isolado de Klebsiella aerogenes pela primeira vez como citado (Soares et al, 2020) e o gene bla $a_{\mathrm{SPM}}$. Os genes bla $a_{\mathrm{KPC}}$, bla $a_{\mathrm{VIM}}$ e bla $a_{\mathrm{NDM}}$ foram os mais comuns relatados no estudo, assim como os genes bla $a_{\mathrm{KPC}} \mathrm{e} b l a_{\mathrm{NDM}}$ foram os mais comuns na China (Wang et al., 2018).

Resistência a carbapenemase em gram-negativos tem sido causa de grande preocupação para a saúde pública, tornando-se cada vez mais difíceis de tratar infecções por cepas metalo- $\beta$-lactamases.

\section{Considerações Finais}

As carbapenemases foram frequentes nestes isolados de gram-negativas, principalmente os genes bla $a_{\mathrm{KPC}}$, bla VIM $_{\mathrm{IM}} \mathrm{e}$ bla $_{\mathrm{NDM}}$. O conhecimento sobre a epidemiologia local dessa bactéria produtora de metalo $\beta$-lactamases é fundamental para estabelecer uma estratégia terapêutica apropriada. A prevalência de gram-negativas produtoras de carbapenemase tem se tornado grande preocupação na rotina clínica, uma vez que, o aumento da resistência tem limitado as opções de terapia empírica, tornado-se um desafio o tratamento de infecções anteriormente tratáveis.

\section{Agradecimentos}

Agradecemos a todos os funcionários do Laboratório de Bacteriologia do HR por fornecer os isolados de gramnegativas e ao Instituto Aggeu Magalhães pela infraestrutura e a todos que contribuiu para elaboração do manuscrito. 


\section{Referências}

Agyepong, N., et al. (2018). Multidrug-resistant gram-negative bacterial infections in a teaching hospital in Ghana. Antimicrob Resist Infect Control. 9;7:37.

Araújo B. F., et al. (2018). Hypervirulence and biofilm production in KPC-2-producing Klebsiella pneumoniae CG258 isolated in Brazil. J Med Microbiol. 67(4):523-528.

Baek, J. Y., et al. (2019). Plasmid analysis of Escherichia coli isolates from South Korea co-producing NDM-5 and OXA-181 carbapenemases. Plasmid. 104:102417.

Barbarini, D., et al. (2015). Evaluation of carbapenem-resistant Enterobacteriaceae in an Italian setting: report from the trench. Infect Genet Evol. 30:8-14.

Ben Helal, R., et al. (2018). Occurrence and Characterization of Carbapenemase-Producing Enterobacteriaceae in a Tunisian Hospital. Microb Drug Resist. 24(9):1361-1367.

Benmahmod, A. B, et al. (2019). Prevalence and Mechanisms of Carbapenem Resistance Among Acinetobacter baumannii Clinical Isolates in Egypt. Microb Drug Resist. 25(4):480-488.

Brink, A. J. (2019). Epidemiology of carbapenem-resistant Gram-negative infections globally. Curr Opin Infect Dis. 32(6):609-616.

Carvalho-Assef, A. P, et al. (2013). Isolation of Providencia rettgeri producing NDM in Brazil. J Antimicrob Chemother. 68 : 2956 - 2957.

Castanheira, M, et al.. (2020). Meropenem-Vaborbactam Activity against Carbapenem-Resistant Enterobacterales Isolates Collected in U.S. Hospitals during 2016 to 2018. Antimicrob Agents Chemother. 64(2). pii: e01951-19.

Cuaical-Ramos, N. M, et al. (2019). Genetic variability of carbapenemase KPC-producing Klebsiella pneumoniae isolated at different states in Venezuela. Variabilidad genética de Klebsiella pneumoniae con carbapenemasa tipo KPC proveniente de diferentes estados de Venezuela. Enferm Infecc Microbiol Clin. 37(2):76-81.

Dirar, M, et al.. (2020). Resistance Patterns and Phenotypic Detection of $\beta$-lactamase Enzymes among Enterobacteriaceae Isolates from Referral Hospitals in Khartoum State, Sudan. Cureus. 13;12(3):e7260.

Dretler, A.W, et al. (2020). High Rates of New Delhi Metallo- $\beta$-Lactamase Carbapenemase Genes in Multi-Drug Resistant Gram-Negative Bacteria in Nicaragua. Am J Trop Med Hyg. 102(2):384-387.

Escandón-Vargas, K, et al. (2017). The epidemiology of carbapenemases in Latin America and the Caribbean. Expert Rev Anti Infect Ther. $15(3): 277-297$.

Ferreira, A M, et al. (2016). First report of a clinical isolate of Klebsiella pneumoniae producing metallo- $\beta$-lactamase in New Delhi in Brazil. J Hosp Infect. 94: 73-74.

Firmo, E. F, et al. (2019). Association of blaNDM-1 with blaKPC-2 and aminoglycoside-modifying enzymes genes among Klebsiellapneumoniae, Proteus mirabilis and Serratiamarcescens clinical isolates in Brazil. J GlobAntimicrobResist. 21:255-61

Firmo, E. F, et al. (2020). Association of bla $\mathrm{NDM}-1_{1}$ with bla $\mathrm{KPC}-2_{2}$ and aminoglycoside-modifying enzyme genes among Klebsiella pneumoniae, Proteus mirabilis and Serratia marcescens clinical isolates in Brazil. J Glob Antimicrob Resist. 21:255-261

Flores, C, et al. (2020). Genetic Relatedness of NDM-Producing Klebsiella pneumoniae Co-Occurring VIM, KPC, and OXA-48 Enzymes from Surveillance Cultures from an Intensive Care Unit. Microb Drug Resist. 26(10):1219-1226

Girija, S A, et al. (2018). Prevalence of VIM- and GIM-producing Acinetobacter baumannii from patients with severe urinary tract infection. Acta Microbiol Immunol Hung. 65(4):539-550

Hagemann, J. B, et al. (2018). KPC-2 carbapenemase-producing Pseudomonas aeruginosa reaching Germany. J Antimicrob Chemother. 1;73(7):1812-1814

Hassuna, N. A, et al. (2020). Molecular Epidemiology and Mechanisms of High-Level Resistance to Meropenem and Imipenem in Pseudomonas aeruginosa. Infect Drug Resist. 13:285-293

Iovleva, A., \& Doi, Y. (2017). Carbapenem-Resistant Enterobacteriaceae. Clin Lab Med. 37(2):303-315

Kiaei, S, et al.. (2019). Emergence of co-existence of bla burning center from southeast of Iran. Folia Microbiol (Praha). 64(1):55-62

Labarca, J. A., et al. (2016). Carbapenem resistance in Pseudomonas aeruginosa and Acinetobacter baumannii in the nosocomial setting in Latin America. Crit Rev Microbiol. 42(2):276-92

Logan, L. K., \& Weinstein, R. A. (2017). The Epidemiology of Carbapenem-Resistant Enterobacteriaceae: The Impact and Evolution of a Global Menace. $J$ Infect Dis. 15;215(suppl_1):S28-S36

Lopes, E, et al. (2020). Epidemiology of carbapenemase-producing Klebsiella pneumoniae in northern Portugal: Predominance of KPC-2 and OXA-48. J Glob Antimicrob Resist. (20):30101-6

Mendes, R. E., et al. (2007). Rapid detection and identification of metallo-beta-lactamase-encoding genes by multiplex real-time PCR assay and melt curve analysis. J ClinMicrobiol. 45(2):544-7. 10.1128/JCM.01728-06.

Merradi, M, et al. (2019). Occurrence of VIM-4 metallo- $\beta$-lactamase-producing Pseudomonas aeruginosa in an Algerian hospital. J Infect Dev Ctries. 13(4):284-290. 
Mohapatra, D. P, et al.. (2018). Extensively drug-resistant and pandrug-resistant Gram-negative bacteria in a tertiary-care hospital in Eastern India: A 4-year retrospective study. J Glob Antimicrob Resist. 15:246-249

Nordmann, P., et al. (2011). Global spread of carbapenemase producing Enterobacteriaceae. Emerg Infect Dis 17:1791-1798

Nordmann, P., \& Poirel, L. (2019). Epidemiology and Diagnostics of Carbapenem Resistance in Gram-negative Bacteria. Clin Infect Dis. 13;69(Suppl 7):S521-S528

Oteo, J, et al. (2013). Spanish Collaborating Group for the Antibiotic Resistance Surveillance Program. Carbapenemase-producing enterobacteriaceae in Spain in 2012. Antimicrob Agents Chemother. 57(12):6344-7.

Pacheco, T., et al. (2019). Pseudomonas aeruginosa Coharboring BlaKPC-2 and BlaVIM-2 Carbapenemase Genes. Antibiotics (Basel) 20;8(3). pii: E98.

Papadimitriou-Olivgeris. M, et al. (2019). Reversal of carbapenemase-producing Klebsiella pneumoniae epidemiology from blaKPC- to blaVIM-harbouring isolates in a Greek ICU after introduction of ceftazidime/avibactam. J Antimicrob Chemother. 1;74(7):2051-2054

Peirano, G, et al. (2018). Genomic epidemiology of global Carbapenemase - producer of Enterobacter spp., 2008-2014. Emerg Infect Dis. (6):1010-1019

Petrova, A. P, et al. (2017). Carbapenemase Production of Clinical Isolates Acinetobacter baumannii and Pseudomonas aeruginosa from a Bulgarian University Hospital. Folia Med (Plovdiv). 20;59(4):413-422.

Poirel, L., et al. (2012). Genetic Features of the Widespread Plasmid Coding for the Carbapenemase OXA-48. Antimicrob Agents Chemother. 56 (1): $559-562$. 10.1128 / AAC.05289-11

Sah, R, et al. (2019). Detection of Pan drug resistance OXA-48 producing Providencia in an ICU patient for the first time in Nepal. AntimicrobResistInfectControl. 8:155.

Senchyna, F, et al. (2019). Diversity of resistance mechanisms in carbapenem-resistant Enterobacteriaceae at a health care system in Northern California, from 2013 to 2016. Diagn Microbiol Infect Dis. 93(3):250-257

Simner, P. J, et al. (2017). Carbapenemase Detection among Carbapenem-Resistant Glucose-Nonfermenting Gram-Negative Bacilli. J Clin Microbiol. 55(9):2858-2864

Soares, C. R. P., et al. (2020). First report of a bla $\mathrm{NDM}^{-}$-resistant gene in a Klebsiella aerogenes clinical isolate from Brazil. Journal of the Brazilian Society of Tropical Medicine. 21;54:e2622020.

Soliman, A. M, et al. (2020). Genetic analysis of carbapenemase-producing Gram-negative bacteria isolated from a university teaching hospital in Egypt. Infect Genet Evol. 77:104065.

Telling, K., et al. (2018). Multidrug resistant Pseudomonas aeruginosa in Estonian hospitals. BMC Infect Dis. 11;18(1):513

Tian D, et al. (2020). Dissemination of the bla NDM-5 Gene via IncX3-Type Plasmid among Enterobacteriaceae in Children. mSphere. 5(1). pii: e00699-19

Uc-Cachón, A. H., et al.. (2019). High Prevalence of Antimicrobial Resistance Among Gram-Negative Isolated Bacilli in Intensive Care Units at a TertiaryCare Hospital in Yucatán Mexico. Medicina (Kaunas). 13;55(9):588

Wang, C, et al. (2006). An isolate of Pseudomonas aeruginosa that produces the extended spectrum beta-lactamase GES-5. J Antimicrob Chemother. 57 (6): 1261-2. 10.1093 / jac / dk1116

Wang, Q, et al. (2018). Phenotypic and Genotypic Characterization of Carbapenem-resistant Enterobacteriaceae: Data From a Longitudinal Large-scale CRE Study in China (2012-2016). Clin Infect Dis. 13;67(suppl_2):S196-S205

Wilson, H., \& Török, M. E. (2018). Extended-spectrum $\beta$-lactamase-producing and carbapenemase-producing Enterobacteriaceae. Microb Genom. 4(7):e000197.

Yaghi, J, et al. (2020). Unusually High Prevalence of Cosecretion of Ambler Class A and B Carbapenemases and Nonenzymatic Mechanisms in MultidrugResistant Clinical Isolates of Pseudomonas aeruginosa in Lebanon. Microb Drug Resist. 26(2):150-159

Yan, J, et al. (2017). Multidrug Resistance Mechanisms of Carbapenem Resistant Klebsiella pneumoniae Strains Isolated in Chongqing, China. Ann Lab Med. 37(5):398-407

Zeynudin, A., et al.. (2018). Prevalence and antibiotic susceptibility pattern of CTX-M type extended-spectrum $\beta$-lactamases among clinical isolates of gramnegative bacilli in Jimma, Ethiopia. BMC Infect Dis. 20;18(1):524

Zhang, Y., et al. (2018). Epidemiology of Carbapenem-Resistant Enterobacteriaceae Infections: Report from the China CRE Network. Antimicrob Agents Chemother. 25;62(2):e01882-17 